OPEN ACCESS

Edited by:

Paul M. Coussens,

Michigan State University,

United States

Reviewed by:

Aldo Venuti,

Regina Elena National Cancer Institute

(IRCCS), Italy

Guillermo Giovambattista, CONICET Institute of Veterinary Genetics (IGEVET), Argentina

Ramesh Somvanshi,

ICAR, India

*Correspondence:

Sante Roperto

sante.roperto@unina.it

Specialty section

This article was submitted to Veterinary Infectious Diseases,

a section of the journal

Frontiers in Veterinary Science

Received: 16 November 2020

Accepted: 21 April 2021

Published: 09 June 2021

Citation:

Longeri M, Russo V, Strillacci MG

Perillo A, Carisetti M, Cozzi MC,

Neola B and Roperto S (2021) Association Between BoLA-DRB3.2

Polymorphism and Bovine

Papillomavirus Infection for Bladder

Tumor Risk in Podolica Cattle.

Front. Vet. Sci. 8:630089.

doi: 10.3389/fvets.2021.630089

\section{Association Between BoLA-DRB3.2 Polymorphism and Bovine Papillomavirus Infection for Bladder Tumor Risk in Podolica Cattle}

\author{
Maria Longeri ${ }^{1}$, Valeria Russo ${ }^{2}$, Maria Giuseppina Strillacci ${ }^{1}$, Antonella Perillo ${ }^{3}$, \\ Michela Carisetti ${ }^{1}$, Maria Cristina Cozzi ${ }^{1}$, Benedetto Neola ${ }^{4}$ and Sante Roperto ${ }^{2 *}$ \\ ${ }^{1}$ Dipartimento di Medicina Veterinaria, Università degli Studi di Milano, Lodi, Italy, ${ }^{2}$ Dipartimento di Medicina Veterinaria e \\ delle Produzioni Animali, Università degli Studi di Napoli Federico II, Naples, Italy, ${ }^{3}$ Dipartimento di Medicina Veterinaria, \\ Università degli Studi di Bari, Bari, Italy, ${ }^{4}$ Istituto Zooprofilattico Sperimentale del Mezzogiorno, Naples, Italy
}

Blood samples from 260 unrelated cattle (132 animals affected by papillomavirus-associated bladder tumors and 128 healthy) were genotyped using the classic polymerase chain reaction/restriction fragment length polymorphism method to screen MHC class II bovine leukocyte antigen-DRB3. 2 polymorphism. The DRB3*22 allele was significantly $(p \leq 0.01)$ detected in healthy cattle, thus appearing to have a negative association (protective effect) with virus infection of the urinary bladder known to represent a bladder tumor risk for cattle living free at pasture. Considering the two sequence alleles identified in animals carrying DRB3*22, DRB3*011:01 allele from samples of animals harboring the unexpressed bovine papillomaviruses (BPV)-2 E5 gene was characterized by amino acid residues believed to have a protective effect against BPV infection such as arginine at position $71\left(R^{71}\right)$ in pocket 4 , histidine at position 11 $\left(\mathrm{H}^{11}\right)$ in pocket 6 , and both glutamine at position $9\left(\mathrm{Q}^{9}\right)$ and serine at position $57\left(\mathrm{~S}^{57}\right)$ in pocket 9 of the antigen-binding groove. The DRB3*011:02v allele from affected animals was characterized by amino acids believed to be susceptibility residues such as lysine $\left(K^{71}\right)$, tyrosine $\left(Y^{11}\right)$, glutamic acid $\left(E^{9}\right)$, and aspartic acid $\left(D^{57}\right)$ in these pockets. These results suggest that animals harboring the DRB3*011:01 allele may have a lower risk of BPV infection and, consequently, a reduced risk of bladder tumors.

Keywords: bovine papilloma virus type 2, DRB3 exon 2 (DRB3.2), major histocompatibility complex class II (MHC II), bovine leukocyte antigen (BoLA), E5 oncoprotein

\section{INTRODUCTION}

Papillomaviruses (PVs) are a heterogeneous group of small, non-enveloped, double-stranded DNA viruses distributed globally. They infect the mucosal and cutaneous epithelia of vertebrates, resulting in benign and malignant lesions of the skin and mucosa (1).

Bovine papillomaviruses (BPVs) comprise 29 members grouped into five genera [http://pave. niaid.nih.gov/, $(2,3)]$. BPV-1, $-2,-13$, and -14 , considered to be highly pathogenic (4), belong to Deltapapillomavirus genus $(\delta \mathrm{PV})$.

Bovine $\delta \mathrm{PVs}$ are the only BPVs known to be characterized by natural cross-species transmission and infection (1), including a recent congenital infection that resulted in oral fibropapillomatosis 
of newborn lambs (5). Bovine $\delta$ PVs play a central role in bovine and bubaline bladder carcinogenesis $(6,7)$. Indeed urinary bladder tumors are common in adult cattle and water buffaloes reared fully or partially on hilly/mountain pasturelands rich in bracken fern (Pteridium spp.), as the urinary bladder of herbivores is the specific target for bracken genotoxins such as ptaquiloside (PT) (7-10). Indeed PT is responsible for the alkylation of adenine of codon 61 of $\mathrm{H}$ ras gene, resulting in a glutamine 61 substitution that is essential for guanosine triphosphate (GTP) hydrolysis (11). Glutamine substitution at position 61 impairs the intrinsic GTPase activity. Therefore, active GTP-bound conformations (Ras-GTP) accumulate in cells, thereby causing abnormal cell proliferation and differentiation (12).

Bovine $\delta \mathrm{PVs}$ exhibit their transforming activity through the E5 protein, which is the most highly conserved and the smallest known naturally occurring oncoprotein (13). Numerous molecular pathways by which E5 oncoprotein is responsible for cellular transformation of naturally occurring urothelial tumors have been identified. It binds to the transmembrane domain of the platelet-derived growth factor $\beta$ receptor (PDGF $\beta R$ ), causing dimerization and activation of the receptor $(7,14)$. E5 has been shown to be involved in bladder carcinogenesis via PDGF $\beta$ R and calpain 3 activation pathways $(7,15)$. In addition, E5 binds to the $\mathrm{D}$ subunit of the $\mathrm{V}_{1}$-ATPase proton pump (16).

It has been suggested that PT and BPV-2 may act synergistically. PT is an initiation factor responsible for bladder cell hyperplasia, and BPV-2 appears to be a promotion factor (6).

The bovine leukocyte antigen (BoLA) system is the major histocompatibility complex (MHC) of cattle. The MHC genes, mapped to bovine autosome 23, are highly polymorphic and play key roles in immune susceptibility and resistance to pathogens (17). The class II genes encode proteins that present processed antigens to helper $\mathrm{T}$ cells bearing the $\mathrm{CD} 4^{+}$marker differentiation, thus playing an important role in controlling viral diseases (18). A number of studies have reported the association of one or more of the BoLA-DRB3.2 alleles with susceptibility/resistance to some infectious diseases in cattle such as dermatophilosis and bacterial mastitis (19). Furthermore, it has been shown that MHC genes play a crucial role to foot and mouth disease virus infection (20). Moreover, some MHC class II gene polymorphisms have been associated with resistance and susceptibility to bovine leukemia virus infection (21). In particular, some associations between the MHC genes and human papillomavirus (HPV) and BPV infections have been suggested $(22,23)$. These associations influence both susceptibility to and regression of PV infections. It has been shown that MHC class II plays an important role in cervical cancer caused by HPV-16 and HPV-18 $(24,25)$ as well as in horse sarcoids associated with BPV1 and BPV-2 (26). In PV infections, T cell response is believed to be critical for virus clearance (27).

The bovine MHC comprises three DRB class II copies, with the BoLA-DRB3 gene being the most highly expressed, functional, and polymorphic. DRB3 polymorphism is mainly concentrated in the second exon, which encodes the variable portion of the peptide-binding groove (18). It has been suggested that polymorphisms influence both the magnitude and epitope specificity of antigen-specific $\mathrm{T}$ cell responses to infectious diseases. In this sense, the BoLA-DRB3 gene is associated with differences in susceptibility to infectious diseases (17). Antigens are specifically bound via interactions of amino acid residues at specific positions of pockets (P) 1, 4, 6, 7, and 9 of the groove. Every MHC class II allele has a narrow or wider specific affinity of binding for a given peptide depending on its different residues in these five pockets (25).

The present study aimed to investigate the potential risk association between BoLA-DRB3 exon two polymorphism and BPV infection of the urinary bladder, which plays a central role in bladder carcinogenesis in Podolica cattle.

\section{MATERIALS AND METHODS}

\section{Ethics Statement}

We did not perform any animal experiments, and no ethics approval was required.

\section{Animals and Blood Samples}

In this study, we selected and examined 260 blood samples from unrelated cattle that we collected from public slaughterhouses in southern Italy over a span of several years. The samples were from 132 animals suffering from a clinical syndrome called "chronic enzootic hematuria" caused by naturally occurring papillomavirus-associated bladder tumors ("affected") and from 128 apparently healthy cattle without any bladder lesions. E5 oncoprotein encoded by an early viral gene was found only in affected cattle; on the contrary, all healthy cattle harbor papillomavirus DNA only without any expression. All the animals were slaughtered according to the owners' decisions and after veterinary investigations were carried out as antemortem examination in accordance with the national legislation. In both affected and healthy animals, we carried out a post-mortem examination with the permission of the official veterinarian to harvest tissue samples. To prevent possible crosscontaminations, during sampling, both neoplastic and healthy bladder tissues were immediately divided into several parts. Some parts were frozen in liquid nitrogen and stored at $-80^{\circ} \mathrm{C}$ for subsequent molecular biological analysis. The remaining parts were fixed in $10 \%$ buffered formalin for microscopic investigations. Blood samples were obtained during slaughtering procedures in sterile containers and immediately stored in EDTA-containing tubes for each sampled animal. They were kept at a refrigerated temperature up to labs. The clinically normal cattle were from the same affected cattle herds located in hilly/mountainous areas of several regions of southern Italy. The affected group was composed of 4-18-year-old cattle; the clinically normal animal group comprises 2-16-year-old cattle. Both groups shared bracken fern-infested lands. All these as big as hectare scattered rangelands, including greenwood floor vegetation, contained an overabundance of bracken fern (Pteridium aquilinum), the most prevalent variety of fern in Southern Italy. Podolica cattle usually graze ad libitum on these lands covered with fern fronds that represent the most important source of food from May to August when the plant increases 
in density. There are no significant differences in bracken fern exposure among all animals living in these conditions.

Methods to collect samples and detect the presence and expression of BPV-2 in healthy and pathological bladders have been described in detail elsewhere $(7,10,15,28-31)$.

\section{BoLA-DRB3.2 Genotyping and Antigen-Binding Groove Analysis}

Genomic DNA was isolated from $200 \mu \mathrm{l}$ of blood collected in EDTA-containing anticoagulant tubes using the DNeasy ${ }^{\circledR}$ Blood \& Tissue Kit (Qiagen ${ }^{\mathrm{TM}}$, Wilmington, DE, USA) according to the manufacturer's instructions. BoLA-DRB3 exon two was genotyped according to (32). In short, semi-nested PCRs with primers HL030-5'ATCCTCTCTCTGCAGCACATT TCC; HL031-5'TTTAAATTCGCGCTCACCTCGCCGCT (first round) and HL30 and HL032-5'TCGCCGCTGCACAGTGAAA CTCTC (second round) were prepared, and specific amplicons were digested with RsaI, BstYI, and HaeIII run on acrylamide gel. The polymerase chain reaction (PCR)/restriction fragment length polymorphism (RFLP) allelic variants were identified with the combined reading of the three restriction patterns (according to the International Society of Animal Genetics BoLA workshops nomenclature). A subset of 19 samples showing PCR/RFLP allele*22 was cloned using the pMOS blunt-ended PCR cloning kit (GE Healthcare, USA). Clone inserts Sangersequenced both strands using the ABI PRISM BigDye Terminator Cycle Sequencing Ready Reaction Kit (Thermo Fisher, Scientific, Waltham, MA, USA) to determine the sequence allele because this restriction pattern may include more alleles. The nucleotide sequences were multiple-aligned and translated using ClustalW implemented in BioEdit. Amino acid sequences were aligned to all the BoLA-DRB3 protein sequences downloaded from the (33) using the BLAST tool in NCBI. Amino acid residues forming a pocket of the antigen-binding groove in the BoLA-DR were determined by analogy with HLA-DR. In amino acid motif analysis, classification by charge was made by grouping the amino acids into three categories [positive $(\mathrm{R}, \mathrm{H}$, and $\mathrm{K})$, negative (D and $\mathrm{E}$ ), and uncharged (A, N, C, Q, G, I, L, M, F, P, S, T, W, Y, and $\mathrm{V})$ ] and by volume and polarity [one for special (C), two for neutral and small (A, G, P, S, and T), three for polar and relatively small $(\mathrm{N}, \mathrm{D}, \mathrm{Q}$, and $\mathrm{E})$, four for polar and relatively large $(\mathrm{R}, \mathrm{H}$, and $\mathrm{K}$ ), five for non-polar and relatively small (I, L, M, and V), and six for non-polar and relatively large (F, W, and Y)]. Pocket and residue numbers were reported according to (34); amino acid charge, volume, and polarity were reported according to (35).

\section{Statistical Analysis}

PCR/RFLP allele frequencies and residue motifs were calculated by GENEPOP $3.1 \mathrm{~d}$ and compared using $2 \times 2$ contingency tables. The chi-square test (using Yate's continuity correction for the estimation of probability in small samples), $p$-value, odds ratio (OR), and confidence intervals (CI) were calculated by proc GENMOD () 2006 SAS Institute Inc., Cary, NC, USA) and classical formulae. Fisher's exact test was employed to evaluate the difference in the frequency of amino acid residues in affected and healthy animals. For cases showing a statistically significant difference in frequency between affected and healthy animals, relative risk (RR) was calculated using the following equation: $\mathrm{Pd}$ $(1-\mathrm{Pc}) /(1-\mathrm{Pd}) \mathrm{Pc}$, where $\mathrm{Pd}$ and $\mathrm{Pc}$ are frequencies of the amino acid residues, presumed to be the risk factor for virus infection in the affected $(\mathrm{Pd})$ and healthy $(\mathrm{Pc})$ cattle $(34,36)$.

\section{RESULTS}

\section{Virological Findings}

For this study, we selected 260 unrelated cattle, 132 of which were affected by BPV-2-associated bladder tumors and 128 were without any bladder lesions (healthy). We have been studying this group for many years in an ongoing research project examining the relationship between BPV infection and bladder cancerogenesis. From each cattle, we have been routinely collecting bladder and blood samples. In all tumor cattle, BPV2 presence was detected by specific primers, amplifying and sequencing several BPV-2 E5 DNA fragments according to the BPV-2 sequence deposited in GenBank (accession number: M20219.1). Furthermore, in the affected cattle, BPV-2 expression was shown by detecting E5 oncoprotein through both reverse transcription (RT)-PCR showing its transcripts and by Western blot both in bladder tumor and blood samples. In bladder and blood samples from healthy cattle, BPV-2 E5 DNA only was detected by PCR since neither BPV-2 E5 oncoprotein expression by Western blot nor BPV-2 E5 transcripts by RT-PC has ever been shown. All the molecular results were reported elsewhere (7, 10, 15, 29-31). However, in Supplementary Table 1, data about BPV-2 are summarized.

\section{BoLA Alleles}

Overall, 37 PCR/RFLP alleles were identified from 260 animals (Supplementary Table 2), indicating a high variability within the Podolica breed. Eight, namely, DRB3*01, ${ }^{*} 07,{ }^{*} 08,{ }^{*} 10,{ }^{*} 11,{ }^{*} 22$, $* 27$, and $* 28$, showed an allele frequency higher than $5 \%$ and, therefore, were statistically evaluated (Table 1).

Only one allele showed a high significance $(p \leq 0.01)$, namely, $\mathrm{DRB}^{*} 22$, which was found to be prevalent in healthy cattle harboring BPV-2 E5 DNA only without any bladder lesions, which may suggest a negative association with BPV-2 infection, in comparison with the affected cattle in which the BPV-2 E5 gene was expressed. Since the ${ }^{*} 22$ restriction pattern may include more alleles, to understand whether bladder tumor risk in animals with the BoLA DRB3.2*22 allele could be related to differences in the residues of the antigen-binding groove, a subset of ${ }^{*} 22$-carrying samples was cloned and sequenced. Two sequence alleles resulted: BoLA03116|DRB3*011:01 and a variant of BoLA09801|BoLA-DRB3*011:02 according to the IPDMHC website.

The variant DRB3*011:02v differed from DRB3*011:02 only for the substitution of serine (S) with aspartic acid (D) at position 57. Aligning the allele sequences and comparing healthy and affected groups, differences were reported at amino acid residues in three pockets, namely, 4, 6, and 9. An additional residue was different at position 45 in a non-pocket-forming position (Supplementary Table 3).

In particular, arginine $(R)$ was the amino acid residue at position $71\left(\mathrm{Arg}^{71}\right)$ in $\mathrm{P} 4$ of the BoLA-DRB3*011:01 allele 
TABLE 1 | BoLA DRB3.2 PCR/RFLP alleles with a higher frequency than $5 \%$ in 260 animals.

\begin{tabular}{|c|c|c|c|c|c|c|c|}
\hline $\begin{array}{l}\text { PCR/RFLP } \\
\text { DRB3.2* allele }\end{array}$ & Allele $\mathrm{n}$. & Tot Freq & Freq in affected & Freq in healthy & Chi-squared (Yates' correction) & $p$-value & Odds Ratio (95\% C.I.) \\
\hline 1 & 63 & 0.12 & 0.13 & 0.12 & 0.02 & n.s. & $1.08(0.63-1.82)$ \\
\hline 8 & 30 & 0.06 & 0.05 & 0.06 & 0.03 & n.s. & $0.88(0.41-1.83)$ \\
\hline 10 & 33 & 0.06 & 0.08 & 0.05 & 1.82 & n.s. & $1.76(0.84-3.65)$ \\
\hline 27 & 34 & 0.07 & 0.09 & 0.04 & 3.46 & n.s. & $2.13(1.01-4.45)$ \\
\hline 28 & 47 & 0.09 & 0.09 & 0.09 & 0.01 & n.s. & $1.01(0.55-1.84)$ \\
\hline
\end{tabular}

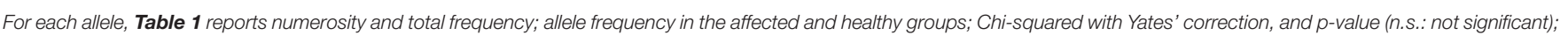
odds ratio and $95 \%$ confidence interval.

of most healthy animals (six of nine, that is 67\%-three of which were homozygous), whereas lysine (K) was the prevailing amino acid residue in this position $\left(\mathrm{Lys}^{71}\right)$ in the affected animals carrying BoLA-DRB3*011:02v (eight out of 10, which is $80 \%)$. Furthermore, with the same percentages, respectively, and consistently due to the linkage between the residues within the alleles (Supplementary Table 3), a large majority of healthy animals with the BoLA-DRB3*011:01 allele in the P6 had histidine $(\mathrm{H})$ as amino acid residue at position 11 (His ${ }^{11}$ ). Tyrosine (Y) was the amino acid residue seen in most affected animals with the BoLA-DRB3* $011: 02 \mathrm{v}$ allele at the same position $\left(\mathrm{Tyr}^{11}\right)$. In addition, in the P9 of healthy animals with the BoLADRB3 $^{*}$ 011:01 allele, glutamine (Q) was the most prevalent amino acid residue at position $9\left(\mathrm{Gln}^{9}\right)$; on the contrary, glutamic acid (E) was the prevalent residue in the BoLA-DRB3*011:02v allele of the affected animals $\left(\mathrm{Glu}^{9}\right)$. Serine $(S)$ was the most prevalent residue at position 57 in the P9 of healthy animals with the BoLA-DRB3*011:01 ( $\mathrm{Ser}^{57}$ ). In affected animals with the BoLA-DRB3*011:02v, aspartic acid (D) was the prevalent amino acid residue in this position $\left(\mathrm{Asp}^{57}\right)$. Finally, in the notpocket-forming position $45, \mathrm{Asp}^{45}$ was the residue mostly found in healthy animals. In affected animals, glycine (G) was found as the prevalent residue in this position $\left(\mathrm{Gly}^{45}\right)$. The amino acid residues and their chemico-physical property differences between healthy and affected animals, as well as BPV infection status, are summarized in Table 2.

Fisher's exact test showed a $p$-value of 0.02 , thus being of statistical significance, and RR, calculated through amino acid residues, was 14.2 in the affected cattle with the BoLADRB3 $^{*}$ 011:02v, which indicated a strong positive association with BPV infection; in healthy cattle with the BoLA-DRB3*011:01, RR was 0.07 , which indicated a very strong negative (protective) association with BPV infection.

\section{DISCUSSION}

The MHC genes are of particular interest because they are associated with genetic resistance and susceptibility to a wide spectrum of economically important diseases in farm animals (37). It has been suggested that some amino acid motifs forming the pockets in the antigen-binding groove of BoLA-DR molecule are involved in conferring resistance or susceptibility to bovine diseases (20, 27, 38-40). In particular, amino acids within P1, P4, P6, P7, and P9 appear to play a crucial role for determining the degree of immune response $(20,34)$.

Although downregulation of $\mathrm{MHC}$ class I is a property common to BPV E5 oncoprotein $(22,41)$, no information concerning the potential associations of BoLA class II variability with BPV-2 infection and bladder tumor risk in cattle is available. Therefore, this is the first study that has investigated the relationship between MHC complex class II DRB3 genes, BPV-2 infection status, and bladder tumor risk in cattle.

Our study showed the peptide polymorphic sequences of BoLA-DRB3*011:01 and BoLA-DRB3*011:02v in several amino acid residues of three pockets. Arg $^{71}$ in P4 was seen in the BoLA-DRB3*011:01 allele in healthy animals, whereas Lys $^{71}$ was found in the BoLA-DRB3*011:02v allele in diseased cattle. It is conceivable that the amino acid $\mathrm{Arg}^{71}$ observed in healthy cattle may be associated with a higher resistance to BPV infection; therefore, these animals may have a lower risk of bladder neoplasia. Indeed RR was indicative of a strong, negative association with BPV infection. Our suggestion is consistent with the results of previous investigations. Indeed it has been shown that $\mathrm{Arg}^{71}$ in P4 is correlated with resistance to persistent lymphocytosis caused by the bovine leukemia virus (42). Furthermore, $\mathrm{Arg}^{71}$ in P4 has been associated with a high resistance to Escherichia coli mastitis in dairy cows (43). Our results appeared to strengthen previous studies suggesting that amino acid residues in $\mathrm{P} 4$ are crucial for resistance and/or susceptibility to diseases (34). In addition, $\operatorname{Ser}^{57}$ and $\mathrm{Asp}^{57}$ were the amino acid residues prevalently found in $\mathrm{P9}$ at position 57 of BoLA-DRB3*011:01 and BoLA-DRB3*011:02v alleles, respectively. It has been suggested that amino acids encoded at position 57 in P9 of DRB3 alleles play a crucial role in modulating HPV infection in humans, thus contributing significantly to HPV16 infection susceptibility and/or resistance. Indeed it has been hypothesized that $\operatorname{Ser}^{57}$ is negatively associated with HPV infection, thus having a protective effect, while Asp ${ }^{57}$ is positively associated to HPV infection, thus contributing significantly to HPV-related cancer risk (44). As in humans, it is conceivable that $\operatorname{Ser}^{57}$ may have a protective effect against 
TABLE 2 | DRB3.2*22 allele and bovine papillomavirus (BPV) infection status.

\begin{tabular}{|c|c|c|c|c|c|c|c|}
\hline allele & & $\begin{array}{l}\text { Pocket } 4 \\
\text { Residue } \\
71\end{array}$ & $\begin{array}{l}\text { Pocket } 6 \\
\text { Residue } \\
11\end{array}$ & $\begin{array}{l}\text { Pocket } 9 \\
\text { Residue } 9\end{array}$ & $\begin{array}{l}\text { Pocket } 9 \\
\text { Residue } \\
57\end{array}$ & $\begin{array}{l}\text { No } \\
\text { Pocket } \\
\text { Residue } \\
45\end{array}$ & $\begin{array}{l}\text { BPV infection: } \\
\text { prevalent status }\end{array}$ \\
\hline BoLA-DRB3*011:01 & $\begin{array}{l}\text { AA } \\
\text { Charge } \\
\text { Volume } \\
\text { Polarity }\end{array}$ & $\begin{array}{l}\text { R } \\
\text { Positive } \\
\text { Relatively } \\
\text { Large } \\
\text { Polar }\end{array}$ & $\begin{array}{l}\mathrm{H} \\
\text { Positive } \\
\text { Relatively } \\
\text { Large } \\
\text { Polar }\end{array}$ & $\begin{array}{l}\text { Q } \\
\text { Uncharged } \\
\text { Relatively } \\
\text { Small } \\
\text { Polar }\end{array}$ & $\begin{array}{l}\text { S } \\
\text { Uncharged } \\
\text { Small } \\
\text { Neutral }\end{array}$ & $\begin{array}{l}\text { D } \\
\text { Negative } \\
\text { Relatively } \\
\text { Small } \\
\text { Polar }\end{array}$ & $\begin{array}{l}\text { BPV E5 DNA only: } \\
\text { No } \\
\text { virus expression }\end{array}$ \\
\hline BoLA-DRB3*011:02v & $\begin{array}{l}\text { AA } \\
\text { Charge } \\
\text { Volume } \\
\text { Polarity }\end{array}$ & $\begin{array}{l}\text { K } \\
\text { Positive } \\
\text { Relatively } \\
\text { Large } \\
\text { Polar }\end{array}$ & $\begin{array}{l}\text { Y } \\
\text { Uncharged } \\
\text { Relatively } \\
\text { Large } \\
\text { Nonpolar }\end{array}$ & $\begin{array}{l}\text { E } \\
\text { Negative } \\
\text { Relatively } \\
\text { Small } \\
\text { Polar }\end{array}$ & $\begin{array}{l}\text { D } \\
\text { Negative } \\
\text { Relatively } \\
\text { Small } \\
\text { Polar }\end{array}$ & $\begin{array}{l}\text { G } \\
\text { Uncharged } \\
\text { Small } \\
\text { Neutral }\end{array}$ & $\begin{array}{l}\text { BPV E5 transcripts } \\
\text { and oncoprotein: } \\
\text { Virus expression }\end{array}$ \\
\hline
\end{tabular}

Differences in amino acid residues between BoLA-DRB3*011:01 (prevalent in cattle harboring BPV DNA only) and BoLA-DRB3*011:02V (prevalent in animals with BPV expression). Pocket and residue numbers are in accordance with Sharif et al. (34), amino acid charge, volume and polarity with (35).

BPV-2 abortive infection of the urinary bladder of cattle, whereas $\mathrm{Asp}^{57}$ of the BoLA-DRB3*011:02v allele may contribute to the susceptibility to BPV-2 infection of the urinary bladder. $\operatorname{Gln}^{9}$ and $\mathrm{Glu}^{9}$ were found in this pocket of BoLA-DRB3*011:01 and BoLA-DRB3*011:02v alleles, respectively. $\mathrm{Gln}^{9}$ may represent a further amino acid motif associated with resistance to virus infection since it has already been shown to play a central role in the resistance to bacterial infection in cattle (43). Furthermore, although this study may indicate a strong positive association between the presence of His ${ }^{11}$ in P6 and the unexpressed BPV E5 gene, the biological significance of this finding remains to be evaluated. Finally, Asp ${ }^{45}$ was a non-pocket residue found in healthy cattle, replacing $\mathrm{Gly}^{45}$ of affected animals, which may corroborate previous studies that suggested that critical immune functions may exist, spanning farther from the binding pockets (45).

Our results are consistent with the suggestion that BoLA class II alleles may influence the immune response to specific BPVencoded epitopes and, thereby, may play a role in BPV infection that is associated with bladder tumor risk in cattle. Our study indicated that an important association between the DRB3.2*22 allele and BPV-2 infection status of the urinary bladder of cattle may exist.

Indeed the sequence analysis of DRB3.2*22 allele both in healthy and affected animals revealed two different sequences: DRB3*011:01 and DRB3*011:02v. DRB3*011:01 appeared to have a significant negative association with BPV-2 expression; thereby, DRB3*011:01 suggested a protective effect against BPV-2 infection, which may indicate that a lower risk of bladder tumor occurs in those animals carrying this sequence. DRB3 $^{*} 011: 02 \mathrm{v}$ appeared to show a positive association with the viral disease as it was prevalently found in affected animals, and the RR correlated with amino acid residues was 8.1, indicating a strong positive association with BPV infection risk. As in humans $(46,47)$, it is conceivable that a strong immunity to BPV infection appears to be dependent on MHC class II polymorphism. Indeed it has been suggested that cell-mediated immune responses by $\mathrm{T}$ cells bearing $\mathrm{CD} 4$ that recognize antigen presented by class II MHC play a crucial role in cancer development by PV infections (48). It is worth noting that the structural analysis of peptides and polymorphism in a comparison study of cattle BoLA-DR and human HLADR revealed a very high homology between them $(49,50)$. Of note is that it has been suggested that the structure and organization of the MHC genes of cattle are very similar to those of the human $\mathrm{MHC}(34,51)$; thereby, ruminant MHC molecules function in a similar manner to human $\mathrm{MHC}$ molecules (17).

We realized that similar to previous investigations of the relationships between BoLA DRB3 and microbe infections carried out, including mastitis pathogens such as streptococci, Escherichia coli, and Staphylococcus aureus $(39,43)$ and virus infection such as bovine leukemia virus and foot and mouth disease $(20,46,52,53)$, the follow-up necessary to render this study ultimately informative rather than speculative is lacking. On the other hand, the lack of a robust followup is believed to be the most important limitation to investigating relationships between cancer risk and HPV infection in human medicine (54). Further studies are needed to better define the role of DRB3* allele polymorphism in $\mathrm{BPV}$ infection which is responsible for severe economic losses in the cattle industry and general animal husbandry. Host susceptibility factors and immune responses are very important but poorly understood determinants of persistence and progression of PV infection (55), which warrants further research in this field.

\section{DATA AVAILABILITY STATEMENT}

The raw data supporting the conclusions of this article will be made available by the authors, without undue reservation.

\section{AUTHOR CONTRIBUTIONS}

SR and ML contributed to the conceptualization. MS, AP, MCa, $\mathrm{MCo}$, and BN contributed to the methodology. ML, VR, and SR contributed to the validation. SR and ML contributed to 
the writing-review and editing. SR took charge of supervision. All authors contributed to the article and approved the submitted version.

\section{FUNDING}

The authors disclose receipt of the following financial support for the research, authorship, and/or publication of this article. This project was partly supported by grants from the Regione Basilicata, the Regione Campania, and Istituto Zooprofilattico Sperimentale del Mezzogiorno.

\section{REFERENCES}

1. IARC. Monographs on the evaluation of carcinogenic risk to human. In: World Health Organization, editors. Human Papillomavirus. Lyon: WHO Press (2007).

2. Yamashita-Kawanishi N, Ito S, Ishiyama D, Chambers JK, Uchida K, Kasuya F, et al. Characterization of bovine papillomavirus 28 (BPV28) and a novel genotype BPV29 associated with vulval papillomas in cattle. Vet Microbiol. (2020) 250:108879. doi: 10.1016/j.vetmic.2020.108879

3. Yamashita-Kawanishi N, Tsuzuki M, Kasuya F, Chang HW, Haga T. Genomic characterization of a novel bovine papillomavirus type 28. Virus Genes. (2020) 56:594-9. doi: 10.1007/s11262-020-01779-9

4. Daudt C, Da Silva FRC, Lunardi M, Alves CBDT, Weber MN, Cibulski SP, et al. Papillomaviruses in ruminants: an update. Transbound Emerg Dis. (2018) 65:1381-95. doi: 10.1111/tbed.12868

5. Roperto S, Russo V, Corrado F, De Falco F, Munday JS, Roperto F. Oral fibropapillomatosis and epidermal hyperplasia of the lip in newborn lambs associated with bovine Deltapapillomavirus. Sci Rep. (2018) 8:13310. doi: 10.1038/s41598-018-31529-9

6. Campo MS, Jarrett WFH, Barron RJ, O’Neil BW, Smith KT. Association of bovine papillomavirus type 2 and bracken fern with bladder cancer in cattle. Cancer Res. (1992) 52:6898-904.

7. Roperto S, Russo V, Ozkul A, Sepici-Dincel A, Maiolino P, Borzacchiello $\mathrm{G}$, et al. Bovine papillomavirus type 2 infects the urinary bladder of water buffalo (Bubalus bubalis) and plays a crucial role in bubaline urothelial carcinogenesis. J Gen Virol. (2013) 94:403-8. doi: 10.1099/vir.0.047662-0

8. Pamukcu AM, Price JM, Bryan GT. Naturally occurring and bracken-fern-induced bovine urinary bladder tumors. Clinical and morphological characteristics. Vet Pathol. (1976) 13:110-22. doi: $10.1177 / 030098587601300205$

9. Carvalho T, Pinto C, Peleteiro MC. Urinary bladder lesions in bovine enzootic haematuria. J Comp Pathol. (2006) 134:336-46. doi: 10.1016/j.jcpa.2006.01.001

10. Roperto S, Borzacchiello G, Brun R, Leonardi L, Maiolino P, Martano M, et al. A review of bovine urothelial tumours and tumour-like lesions of the urinary bladder. J Comp Pathol. (2010) 142:95-108. doi: 10.1016/j.jcpa.2009.08.156

11. Prakash AS, Pereira TN, Smith BL, Shaw G, Seawrigtht AA. Mechanism of bracken fern carcinogenesis: Evidence for H-ras activation via initial adenine alkylation by ptaquiloside. Nat Toxins. (1996) 4:221-7. doi: 10.1002/(SICI)(1996)4:5<221::AID-NT4>3.0.CO;2-Q

12. Schubbert S, Shannon K, Bollag G. Hyperactive Ras in developmental disorders and cancer. Nat Rev Cancer. (2007) 7:295-308. doi: 10.1038/nrc2109

13. DiMaio D, Petti LM. The E5 proteins. Virology. (2013) 445:99-114. doi: 10.1016/j.virol.2013.05.006

14. Karabadzhak AG, Petti LM, Barrera FN, Edwards APB, Moya-Rodríguez A, Polikanov YS. et al. Two transmembrane dimers of the bovine papillomavirus E5 oncoprotein clamp the PDGF? receptor in an active dimeric conformation. Proc. Natl. Acad. Sci. U.S.A. (2017) 114:E7262-1. doi: 10.1073/pnas.1705622114

15. Roperto S, De Tullio R, Raso C, Stifanese R, Russo V, Gaspari $\mathrm{M}$, et al. Calpain3 is expressed in a proteolitically active form in

\section{ACKNOWLEDGMENTS}

The authors wish to thank Dr. G. Salvatore of the Regione Basilicata, Dr. P. Sarnelli of the Regione Campania, Dr. S. Morace of the University of Catanzaro Magna Graecia, and Dr. Gaetano Milone of the ASL Salerno for their technical help.

\section{SUPPLEMENTARY MATERIAL}

The Supplementary Material for this article can be found online at: https://www.frontiersin.org/articles/10.3389/fvets. 2021.630089/full\#supplementary-material

papillomavirus-associated urothelial tumors of the urinary bladder in cattle. PLOS ONE. (2010) 5:e10299. doi: 10.1371/journal.pone. 0010299

16. Roperto S, Russo V, Borzacchiello G, Urraro C, Lucà R, Esposito I, et al. Bovine papillomavirus type 2 (BPV-2) E5 oncoprotein binds to the subunit D of the V1-ATPase proton pump in naturally occurring urothelial tumors of the urinary bladder of cattle. PLoS ONE. (2014) 9:e88860. doi: 10.1371/journal.pone.0088860

17. Takeshima S, Sarai A, Saitou N, Aida Y. MHC class II DR classification based on antigen-binding groove natural selection. Biochem Biophys Res Commun. (2009) 385:137-42. doi: 10.1016/j.bbrc.2009.04.142

18. Amills M, Ramiya V, Norimine J, Lewin HA. The major histocompatibility complex of ruminants. Rev sci tech Off int Epiz. (1998) 17:108-20. doi: 10.20506/rst.17.1.1092

19. Behl JD, Verma NK, Tyagi N, Mishra P, Behl R, Joshi BK. The major histocompatibility complex in bovines: a review. Vet Sci. (2012) 2012:872710. doi: 10.5402/2012/872710

20. Baxter R, Craigmile SC, Haley C, Douglas AJ, Williams JL, Glass EJ. BoLA-DR peptide binding pockets are fundamental for foot-andmouth disease virus vaccine design in cattle. Vaccine. (2010) 28:28-37. doi: 10.1016/j.vaccine.2009.09.131

21. Juliarena MA, Poli M, Sala L, Ceriani C, Gutierrez S, Dolcini G, et al. Association of BLV infection profiles with alleles of the BoLADRB3.2 gene. Anim Genet. (2008) 39: 432-8. doi: 10.1111/j.1365-2052.2008. 01750.x

22. Peng S, Frazer IH, Fernando GJ, Zhou J. Papillomavirus virus-like particles can deliver defined CTL epitopes to the MHC class I pathway. Virology. (1998) 240:147-57. doi: 10.1006/viro.1997.8912

23. Marchetti B, Ashrafi GH, Tsirimonaki E, O’Brien PM, Campo MS. The bovine papillomavirus oncoprotein E5 retains MHC class I molecules in the Golgi apparatus and prevents their transport to the cell surface. Oncogene. (2002) 51:7808-16. doi: 10.1038/sj.onc. 1205885

24. Alaez-Verson C, Berumen-Campos J, Munguía-Saldaña A, Flores-Aguilar H, Guardado-Estrada M, Rodríguez-Gomez A. et al. HPV-16 and HLA-DRB1 alleles are associated with cervical carcinoma in Mexico Mestizo women. Arch. Med. Res. (2011) 42:421-5. doi: 10.1016/j.arcmed.2011.07.002

25. Chuang LC, Hu CY, Chen HC, Lin PJ, Lee B, Lin CY, et al. Associations of human leukocyte antigen class II genotypes with human papillomavirus 18 infection and cervical intraepithelial neoplasia risk. Cancer. (2012) 118:22331. doi: $10.1002 / \mathrm{cncr} .26227$

26. Staiger EA, Tseng CT, Miller D, Cassano JM, Nasir L, Garrik D, et al. Host genetic influence on papillomavirus-induced tumors in the horse. Int J Cancer. (2016) 139:784-92. doi: 10.1002/ijc.30120

27. Bhaskaran M, and ArunKumar, GP. A meta-analysis of association of Human Leukocyte Antigens A, B, C, DR and DQ with Human Papillomavirus 16 infection. Infect. Genet. Evol. (2019) 68:194-202. doi: 10.1016/j.meegid.2018.12.026

28. Roperto S, Brun R, Paolini F, Urraro C, Russo V, Borzacchiello G, et al. Detection of bovine papillomavirus type 2 in the peripheral blood of cattle with urinary bladder tumours: possible biological role. J Gen Virol. (2008) 89:3027-33. doi: 10.1099/vir.0.2008/004457-0 
29. Roperto S, Munday JS, Corrado F, Goria M, Roperto F. Detection of bovine papillomavirus type 14 DNA sequences in urinary bladder tumors of cattle. Vet Microbiol. (2016) 190:1-4. doi: 10.1016/j.vetmic.2016.04.007

30. Roperto S, Russo V, Leonardi L, Martano M, Corrado F, Riccardi MG, et al. Bovine papillomavirus type 13 expression in the urothelial bladder tumours of cattle. Transbound Emerg Dis. (2016) 63:628-34. doi: 10.1111/tbed.12322

31. Roperto S, Russo V, De Falco F, Taulescu M, Roperto F. Congenital papillomavirus infection in cattle: evidence for transplacental transmission. Vet Microbiol. (2019) 230: 95-100. doi: 10.1016/j.vetmic.2019.01.019

32. van Eijk MJ, Stewart-Haynes JA, Lewin HA. Extensive polymorphism of the BoLA-DRB3 gene distinguished by PCR-RFLP. Anim Genet. (1992) 23:48396. doi: 10.1111/j.1365-2052.1992.tb00168.x

33. Immuno Polymorphism Database-Major Histocompatibility Complex (IPDMHC) website, Release 3.4.0.0. Available online at: bhttps://www.ebi. ac.uk/ipd/mhc/allele/list/?group=BoLA\&organism=BoLA\&gene=DRB3 . Papillomavirus Episteme 2017: http://pave.niaid.nih.gov (accessed December 19, 2019).

34. Sharif S, Mallard BA, Sargeant JM. Presence of glutamine at position 74 of pocket 4 in the BoLA-DR antigen binding groove is associated with occurrence of clinical mastitis caused by Staphylococcus species. Vet Immunol Immunopathol. (2000) 76:31-238. doi: 10.1016/S0165-2427(00)00216-6

35. Dagan T, Talmor Y, Graur D. Ratios of radical to conservative amino acid replacement are affected by mutational and compositional factors and may not be indicative of positive Darwinian selection. Mol Biol Evol. (2002) 19:1022-5. doi: 10.1093/oxfordjournals.molbev.a004161

36. Zerva L, Cizman B, Mehra NK, Alahary SK, Murali R, Zmijewski CM, et al. Arginine at positions 13 or 70-71 in pocket 4 of HLA-DRB1 is associated with susceptibility to tuberculoid leprosy. J Exp Med. (1996) 183:829-36. doi: 10.1084/jem.183.3.829

37. Takeshima SN, Aida Y. Structure, function and disease susceptibility of the bovine major histocompatibility complex. Anim Sci J. (2006) 77:138-50. doi: 10.1111/j.1740-0929.2006.00332.x

38. Brown JH, Jardetzky TS, Gorga JC, Stern LJ, Urban RG, Strominger JL, et al. Three-dimensional structure of human class II histocompatibility antigen HLA-DR1. Nature. (1993) 364:33-9. doi: 10.1038/364033a0

39. Yoshida T, Mukoyama H, Furuta H, Kondo Y, Takeshima SN, Aida Y, et al. Associations of BoLA-DRB3 alleles identified by a sequence-based typing method with mastitis pathogens in Japanese Holstein cows. Anim Sci J. (2009) 80:498-509. doi: 10.1111/j.1740-0929.2009.00663.x

40. Gowane GR, Sharma AK, Sankar M, Narayanan K, Das B, Subraniam S, et al. Association of BoLA DRB3 alleles with variability in immune response among the crossbred cattle vaccinated for foot-and-mouth disease (FMD). Res Vet Sci. (2013) 95:156-63. doi: 10.1016/j.rvsc.2013.03.001

41. Ashrafi GH, Tsirimonaki E, Marchetti B, O’Brien PM, Sibbet GJ, Andrew L, et al. Down-regulation of $\mathrm{MHC}$ class I by bovine papillomavirus E5 oncoproteins. Oncogene. (2002) 21:248-59. doi: 10.1038/sj.onc. 1205008

42. Xu A, van Eijk MJT, Park C, Lewin HA. Polymorphism in BoLA DRB3 exon 2 correlates with resistance to persistent lymphocytosis caused by bovine leukemia virus. J Immunol. (1993) 151:6977-85.

43. Yoshida $T$, Mukoyama H, Furuta H, Kondo $Y$, Takeshima SN, Aida Y, et al. Association of the amino acid motifs of BoLADRB3 alleles with mastitis pathogens in Japanese Holstein cows. Anim Sci J. (2009) 80:510-9. doi: 10.1111/j.1740-0929.2009. 00664.x
44. Apple JR, Erlich HA, Klitz W, Manos MM, Becker TM, Wheeler C. HLA DR-DQ associations with cervical carcinoma show papillomavirus-type specificity. Nat Genet. (1994) 6:157-62. doi: 10.1038/ng0294-157

45. Gerasimou P, Nicolaidou V, Skordis N, Picolos M, Monos D, Costeas PA. Combined effect of glutamine at position 70 of HLA-DRB1 and alanine at position 57 of HLA-DQB1 in type 1 diabetes: An epitope analysis. PLoS ONE. (2018) 13:e0193684. doi: 10.1371/journal.pone.0193684

46. Gerner W, Hammer SE, Wiesmüller KH, Saalmüller A. Identification of major histocompatibility complex restriction and anchor residues of foot-andmoot disease virus-derived bovine T-cell epitopes. J Virol. (2009) 83:4039-50. doi: 10.1128/JVI.01534-08

47. Luckey D, Weaver EA, Osborne DG, Billadeau DD, Taneja V. Immunity to influenza is dependent on MHC II polymorphism: study with 2 HLA transgenic strains. Sci Rep. (2019) 9:19061. doi: 10.1038/s41598-019-55503-1

48. Stanley MA. Immunobiology of papillomavirus. In: Campo MS, editors. Papillomavirus Research - From Natural History to Vaccines and Beyond. Norfolk: Caister Academic Press. (2006) 311-9.

49. Andersson L, Sigurdardóttir S, Borsch C, Gustafsson K. Evolution of MHC polymorphism: extensive sharing of polymorphic sequence motifs between human and bovine DRB alleles. Immunogenetics. (1991) 33:185-93. doi: 10.1007/BF01719239

50. Sigurdardóttir S, Borsch C, Gustafsson K, Andersson L. Cloning and sequence analysis of $14 \mathrm{DRB}$ alleles of the bovine major histocompatibility complex by using the polymerase chain reaction. Anim Genet. (1991) 22:199-209. doi: 10.1111/j.1365-2052.1991.tb00670.x

51. Mosafer J, Heydarpour M, Manshad E, Russel G, Sulimova GE. Distribution of BoLA-DRB3 allelic frequencies and identification of two new alleles in Iranian buffalo breed. Sci World J. (2012) 2012:863024. doi: 10.1100/2012/863024

52. Takeshima SN, Ohno A, Aida Y. Bovine leukemia virus proviral load is more strongly associated with bovine major histocompatibility complex class II DRB3 polymorphism than with DQA1 polymorphism in Holstein cow in Japan. Retrovirology. (2019) 16:14. doi: 10.1186/s12977-019-0476-Z

53. Forletti A, Lützelschwab MC, Cepeda R, Esteban EN, Gutiérrez SE. Early events following bovine leukemia virus infection in calves with different alleles of the major histocompatibility complex DRB3 gene. Vet. Res. (2020) 51:4. doi: 10.1186/s13567-019-0732-1

54. Adebamowo SN, Adeyemo AA, ACCME, Research Group as part of the H,Africa, Consortium. Classical HLA alleles are associated with prevalent and persistent cervical high-risk HPV infection in Africa women. Hum Immunol. (2019) 80:723-30. doi: 10.1016/j.humimm.2019.04.011

55. IARC. Monographs on the evaluation of carcinogenic risk to human. In: World Health Organization, editors. Biological Agents - A Review of Human Carcinogens. Lyon: WHO Press (2012).

Conflict of Interest: The authors declare that the research was conducted in the absence of any commercial or financial relationships that could be construed as a potential conflict of interest.

Copyright (C) 2021 Longeri, Russo, Strillacci, Perillo, Carisetti, Cozzi, Neola and Roperto. This is an open-access article distributed under the terms of the Creative Commons Attribution License (CC BY). The use, distribution or reproduction in other forums is permitted, provided the original author(s) and the copyright owner(s) are credited and that the original publication in this journal is cited, in accordance with accepted academic practice. No use, distribution or reproduction is permitted which does not comply with these terms. 